Provided for non-commercial research and education use. Not for reproduction, distribution or commercial use.

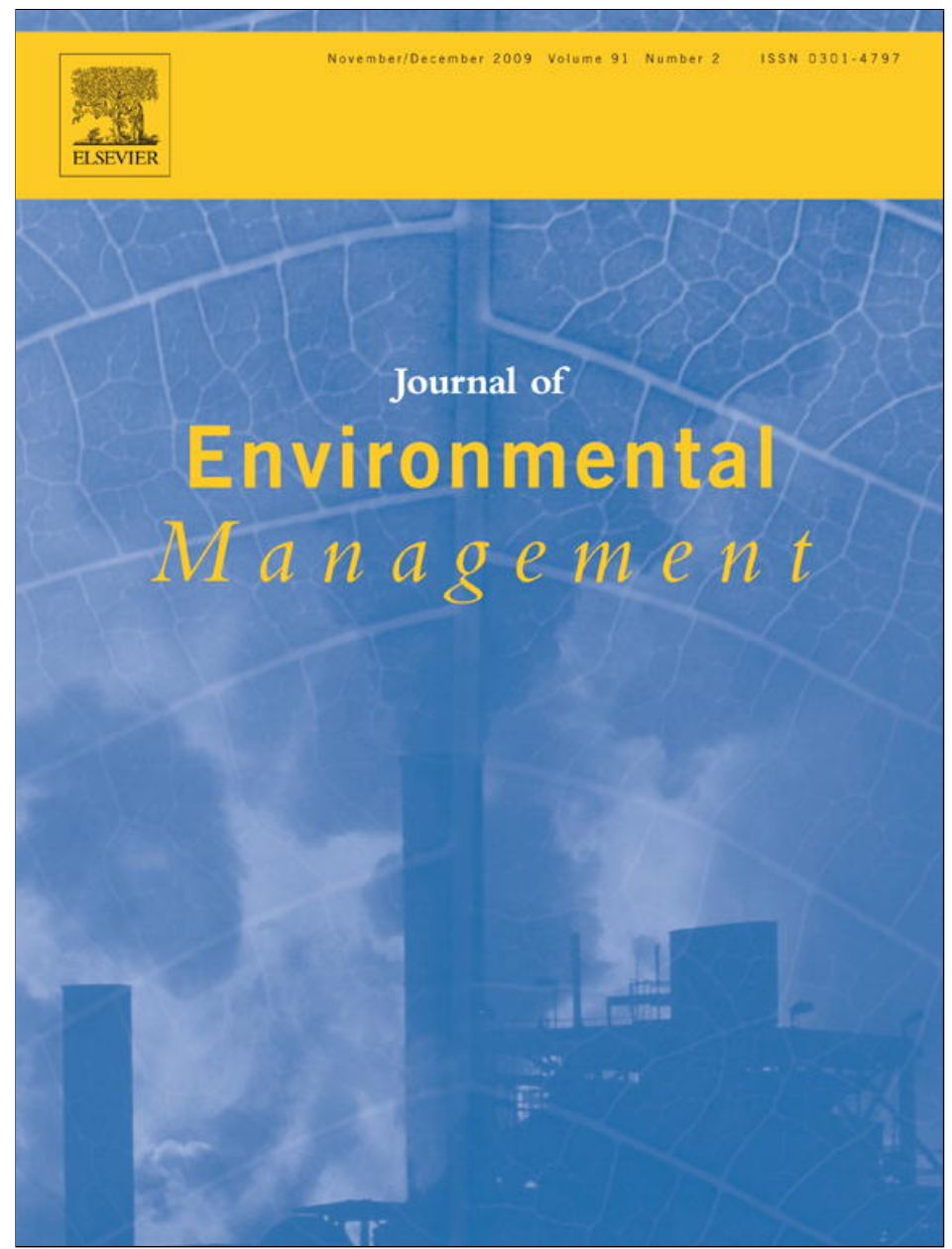

This article appeared in a journal published by Elsevier. The attached copy is furnished to the author for internal non-commercial research and education use, including for instruction at the authors institution and sharing with colleagues.

Other uses, including reproduction and distribution, or selling or licensing copies, or posting to personal, institutional or third party websites are prohibited.

In most cases authors are permitted to post their version of the article (e.g. in Word or Tex form) to their personal website or institutional repository. Authors requiring further information regarding Elsevier's archiving and manuscript policies are encouraged to visit:

http://www.elsevier.com/copyright 


\title{
Mobilizing citizen effort to enhance environmental outcomes: A randomized controlled trial of a door-to-door recycling campaign
}

\author{
Sarah Cotterill*, Peter John, Hanhua Liu, Hisako Nomura \\ University of Manchester, Institute for Political and Economic Governance (IPEG), School of Social Sciences, University of Manchester, Oxford Road, Manchester M13 9PL, UK
}

\section{A R T I C L E I N F O}

\section{Article history:}

Received 19 May 2009

Received in revised form

20 August 2009

Accepted 1 September 2009

Available online 12 October 2009

\section{Keywords:}

Canvassing

Recycling

Experiment

Randomized controlled trial

\begin{abstract}
A B S T R A C T
This paper uses a randomized controlled trial to test whether doorstep canvassing can raise participation in kerbside recycling. Existing research shows that canvassing can confront negative attitudes, increase understanding and resolve structural obstacles, but there is less known about the longitudinal effects of such interventions, which may fall away over time. 194 streets in Trafford, in the North West of England, UK were randomly assigned into a treatment and a control group. All households in the treatment group were visited by canvassers who were trained to promote and encourage recycling. Recycling participation rates for all households were measured by observing bin set out rates over a three-week period. Measurement was done before and after the canvassing campaign and then again three months later to see if the intervention had been effective in raising participation rates. Random-effects multilevel regression models, controlling for baseline recycling, street size, deprivation and size of ethnic minority population, show that the canvassing raised recycling participation rates for the treatment group compared to the control group, but there was a decline in the impact of the intervention over time. The intervention was more effective on streets with low levels of recycling at baseline.
\end{abstract}

(c) 2009 Elsevier Ltd. All rights reserved.

\section{Introduction}

It is widely acknowledged that the actions of citizens are essential to implement policies for a better environment, largely through modifying their individual behaviours (Jackson, 2005). Creating environmentally positive outcomes is a massive task for the twenty-first century as societies across the planet face the challenge of dealing with climate change and disposing of the products of an increasingly consumerist society. It is possible that much of the change will happen through growing awareness of the problems, in reaction to market incentives, or in response to information and regulation from government and other actors. But it is also likely that interventions will be needed, which involve some direct contact with the citizens. While some of these could be the result of demonstration projects or the recruiting of community champions, it is likely that face-to-face contact between an advocate and the citizens has a good chance of achieving a desirable outcome. The state or the voluntary sector may recruit a body of activists to mobilize the citizens to behave differently, much in a similar way that canvassing can get people to vote, for example

\footnotetext{
* Corresponding author. Tel.: +44 161275 0792; fax: +44 1612750793.

E-mail addresses: sarah.cotterill@manchester.ac.uk (S. Cotterill),Peter.John@ manchester.ac.uk (P. John), Hanhua.Liu@manchester.ac.uk (H. Liu), Hisako.Nomura3@manchester.ac.uk (H. Nomura).
}

(Green and Gerber, 2008). The voting literatures and existing studies suggest an effect based on the communication of information in a face-to-face context, a degree of persuasion and taking an interest in the person. With some activities, such as change in car use, it is hard to imagine such a change taking place without a considerable effort in persuasion. But many other activities require modest lifestyle adjustments, with reminders and cues being effective at bringing about behaviour change. Here kerbside recycling is such an activity, where households leave out recyclable waste for collection by the local authority.

This paper provides an experimental test of an intervention designed to increase recycling. A number of studies have been conducted to test the effectiveness of different interventions to raise participation in kerbside recycling schemes, comparing areas or households with or without the intervention (examples include Bryce et al., 1997; Timlett and Williams, 2008; Woodward et al., 2005). Schultz (1998) conducted a randomized controlled trial examining the impact on recycling behaviour of providing written feedback on individual and neighbourhood recycling behaviour. Lyas et al. (2004) undertook a randomized controlled trial to examine the impact of different types of motivational leaflets. This paper presents a randomized controlled trial to test the impact of a door-to-door canvassing campaign. Streets in the research area were randomly assigned into a treatment and control group. All households in the treatment group were visited by canvassers who 
promoted recycling, while households in the control streets received no special attention. Recycling participation rates for all households were measured by observing which households put out a recycling container for collection over a three-week period. Measurement was done before the canvassing campaign and then repeated immediately after the canvassing and again three months later. This is the first randomized controlled trial to measure the impact of a door-to-door canvassing campaign on recycling participation, examining the effects three months after the intervention in order to understand the longer term impact of such an intervention rather than a short-term fillip.

The paper first reviews the literature on interventions designed to improve kerbside recycling, the contribution of street effects, the role of habit, the importance of baseline rates and the impact of socio-demographic variables on recycling behaviour. Following the CONSORT guidelines for reporting randomized controlled trials (Moher et al., 2001), it then sets out the research design and methods, describes the analytical approach, reports the results of the experiment, and then concludes with a discussion of the implications of the findings for recycling and mobilization campaigns and policy.

\section{Background}

\subsection{Interventions to raise participation}

There are a number of potential approaches to encouraging recycling. They range in type, appealing to different kinds of motivation. Promotional and educational campaigns can raise participation rates by ensuring people understand the scheme and motivating people to get involved. High visibility events and roadshows can be successful in building awareness (Read, 1999). Incentives can work in areas with low recycling participation rates (Harder et al., 2006), but they may crowd out intrinsic motivation (Bryce et al., 1997); a recent survey of householders in London found that financial incentives are likely to be less effective in encouraging recycling than recycling scheme improvements and active promotion (Shaw and Maynard, 2008). Feedback cards left by collection crews to highlight boxes that contain contaminated material can be effective in reducing the amount of contamination and it is a cheap approach (Timlett and Williams, 2008). A few studies have tried to change recycling behaviour by activating personal or social norms. The provision of feedback on boroughwide recycling participation rates had no effect in changing householder behaviour in a London borough (Lyas et al., 2004), but giving more specific feedback on the recycling activity of the individual household or the surrounding streets was successful in promoting recycling in a US study (Schultz, 1998).

The method adopted in the current research is doorstep canvassing: there is no compulsion, just the direct approach by a friendly and engaging team. Such kinds of intervention have increased participation in elections by about 7 percent in the UK (John and Brannan, 2008); replicating the effect sizes in US studies (Green and Gerber, 2008). Face-to-face contact on the doorstep is more effective than simply providing literature (Bryce et al., 1997; Reams and Ray, 1993). Door-stepping has not been found to be effective in increasing set out rate or reducing contamination in areas where recycling is already high ( $>60$ percent of households) but it does raise the range of materials recycled (Timlett and Williams, 2008). A study of student housing found that pledges secured through personal contact led to higher recycling rates than pledges through indirect contact or providing information (Bryce et al., 1997; Reams and Ray, 1993), reinforcing the usefulness of a door-todoor campaign.

\subsection{Street and area effects}

The unit of the intervention needs to fit in with the actual spaces that people live in, which can be blocks, streets or neighbourhoods. Streets are important units of analysis because they are reference groups for households, and the place where their behaviour may be observable by neighbours. Theories of collective action imply that the members of a unit, such as a street, will tend to act in relationship to each other: households are more likely to recycle if they see that others in their street are doing the same and they may be influenced by social norms that develop over recycling as more people do it. Of course, streets may be too big to serve this purpose with too many households split up by natural breaks within the street.

Several studies evaluate the spatial scale of recycling. Tucker (1999) examined the impact of social norms within streets, using data from five newspaper recycling schemes in Northern England and Scotland. They found that there is a normative influence households are more likely to set out a recycling box if others in their street recycle regularly. Living on a street with high participation rates may encourage non- or infrequent recyclers to regularly recycle small amounts of material, rather then increasing the absolute amount of material recycled (Tucker, 1999). Shaw (2008) monitored the recycling behaviour of 1700 households in a London borough. Contiguous blocks of households were identified by sectioning streets, taking account of road intersections, open spaces, non-domestic buildings etc. In shorter contiguous blocks (less than 15 houses) householders were influenced by the recycling actions of their nearest next door neighbours, particularly in cul-de-sacs. The influence of neighbours diminished as the length of the blocks increased (Shaw, 2008). Harder et al. (2006) found that households on small roads tend to have a higher recycling participation rate. Suggested factors include increased attachment to the neighbourhood, community spirit and peer pressure, but the reasons are not explored in depth and this is identified as a potential area for future research.

Recycling, like other behaviours, takes place in nested contexts including streets and neighbourhoods where people are clustered together; households within those contexts have some similarities along social dimensions such as levels of income and the composition of those neighbourhoods by different ethnic and social groups. These nested features of individual actions have implications for the study design and the statistical modelling. We chose a street based research design to avoid the contamination that might have arisen if randomization was done at a household level and we conducted the analysis at both the street and super output area ${ }^{1}$ level.

\subsection{Habit}

Less discussed in the literature is the importance of habit and how this may interact with a recycling campaign. Recycling is itself habitual, involving regular sets of activities at the same time of the week. Once a pattern is in train, then by doing the act, it then becomes normal and occurs without thinking. If a campaign succeeds in raising recycling, new habits may form and persist into the future, without the need for on-going persuasion but done as a reflex action. Psychological studies of "foot in the door" techniques seem to reinforce this: current participation makes future participation more likely (Cialdini et al., 1995; Freedman and Fraser, 1966), which is based on strengthening self-perception with people

\footnotetext{
${ }^{1}$ Super output areas are boundaries used by the UK Office for National Statistics to provide statistics at a local level.
} 
determining their attitudes from observing their own behaviour (Beaman et al., 1983; Burger and Caldwell, 2003). To these positive effects of doorstep campaigning on recycling habits, we should also pose the contrary hypothesis - that changes to behaviour might be temporary, with citizens returning to their long-term habits. That raises the question about how long the habit effect lasts for, and how many months after which we might expect the effects of a door-to-door campaign to dissipate. Promotional campaigns tend to be most effective in the short term, with a high initial rise in response to a campaign and a falling off over time (Timlett and Williams, 2008; Woodward et al., 2005). Despite this recycling decay an effect can still be measured several months later (Woodward et al., 2005).

\subsection{The importance of the baseline}

Given the importance of habit, we may expect that interventions will need to work with different starting points that will be hard to shift. Thus those with high levels of activity may carry on in that vein; and so too those who have not such a high participation rate. While shifting habit is hard, it is likely that different levels of recycling may react to the treatment in different ways. Arceneaux and Nickerson (2009) theorize that there are different relationships between the propensity to vote and the impact of a mobilization campaign. Aggregating the results across eleven vote experiments, they find that the lower baseline increases the impact of the treatment, though this is weakened at very low baselines. With recycling, it is likely that a lower baseline will offer more susceptibility to treatment because a campaign is likely to provide information and incentive to act differently.

\subsection{The covariates of recycling}

Like any public action, recycling is affected by socio-demographic variables. Surveys indicate that non-recyclers tend to be younger, less affluent and live in rented accommodation, while recyclers, in contrast, tend to be more mature, more affluent, home owners and better educated (see Martin et al., 2006 for a review). It may be that households from lower socio-economic groups tend to devote less effort to recycling because their poverty and disadvantage mean they face more pressing needs (Martin et al., 2006). Neighbourhoods with a high proportion of ethnic minorities tend to have lower recycling rates, but these often coincide with areas of high deprivation and mobility and little research has been done to separate out these effects. Case studies in two ethnically diverse areas of the UK found that ethnic origin had no significant effect on the participation of individuals in kerbside recycling (Martin et al., 2006; Perry and Williams, 2007). For those who did not recycle, the main reasons were not having a box, not being sure of the collection day or other barriers like lack of space and lack of understanding, suggesting that recycling can be promoted by making it easy to do and providing encouragement and information (Perry and Williams, 2007). There is some limited evidence that transience is an issue here (Perry and Williams, 2007). It is likely that neighbourhoods with high levels of deprivation and a high proportion of ethnic minorities also have a high population turnover. Households moving to an area for the first time are unlikely initially to understand the local waste management system and they may have more immediate demands on them than mastering a system involving a number of different waste containers and collection days. In these circumstances, it might be advantageous for service providers to target canvassing campaigns in areas of high population turnover. This again points to the importance of baseline interactions.

\section{Research design and methods}

\subsection{Research objectives}

The rationale for the study is that a field-force can appeal to people's environmental motivations reminding them of their underlying willingness to contribute. While previous experiments have examined the impact of written feedback (Lyas et al., 2004; Schultz, 1998) or leaflets and pledges (Bryce et al., 1997), this is the only field experiment to measure the impact of canvassing on kerbside recycling and it is the first to consider the longitudinal effect of an intervention to raise recycling. The central research question is to ask whether, to what degree and for how long a door-to-door campaign can raise the recycling level, in particular, we expect that the canvass group will have a higher level of street level recycling than the control group after the canvassing campaign $\left(\mathrm{H}_{1}\right)$. We also test the idea that the intervention is sustained over time and households get into the habit of recycling. So we expect the canvass group will have a higher level of recycling than the control group over time $\left(\mathrm{H}_{2}\right)$. Finally, we expect the treatment to vary according to the baseline rate, with a higher response at lower baseline rates $\left(\mathrm{H}_{3}\right)$.

\subsection{The study site}

We focused on one geographical area in which to carry out the research because of the prohibitive cost of visiting a more dispersed population and to ensure that all households were provided with the same recycling service. There is no reason to believe the area we selected is very different from others of its type, or that we would observe very different effects in other cities in the UK. The research was conducted in two adjoining neighbourhoods, Old Trafford and Gorse Hill, which are within Trafford Council, close to inner city Manchester. Old Trafford is closest to Manchester City Centre. It is an ethnically diverse area. Among our sample streets in Old Trafford, 47 per cent of its residents are from an ethnic minority, predominantly of Pakistani, Indian and Caribbean heritage. It is a relatively deprived area: 7 of the 10 super output areas in Old Trafford are within the lowest 20 per cent of all areas in England in terms of multiple indicators of deprivation and 3 areas are within the lowest 6 per cent. Most of the housing is traditional low-rise properties, both terraced and semi-detached. Gorse Hill is further from the City Centre. It is less ethnically diverse, with 13 per cent of residents being from an ethnic minority. It is relatively deprived in national terms, but less deprived than Old Trafford: its 5 super output areas are in the lowest 20-30 per cent of areas in England. Most of the housing is traditional semi-detached and terraced. Table 1 gives the background statistics.

Table 1

Neighbourhood statistics for Old Trafford and Gorse Hill.

\begin{tabular}{lllc}
\hline & & Old Trafford & Gorse Hill \\
\hline Ethnicity (2001 census) & White & $52.6 \%$ & $87.2 \%$ \\
& Non white & $47.4 \%$ & $12.8 \%$ \\
Multiple deprivation score & & 0.417 & 0.306 \\
$\quad$ (higher score indicates & & \\
$\quad$ more deprived) (2007) & & \\
All data from UK Office of National Statistics & & \\
http://www.neighbourhood.statistics.gov.uk accessed 17/09/08 & \\
\hline
\end{tabular}

\subsection{The recycling service}

The kerbside recycling service is provided by EMERGE, a social enterprise commissioned by Trafford Council to provide a weekly recycling service to the target streets. It collects a very broad variety 
of materials: households have a box (for glass bottles, cans, thin card, directories and textiles) with three separate bags for paper, plastic bottles and batteries. The box system offered here is probably easier for the terraced households, where wheeled bins are problematic because of storage and access issues, but they may be less convenient for the houses with driveways. Households have a weekly recycling collection. There is currently no co-ordination with the council's residual waste collection, so some households may have collections on two different days each week. The vehicle collecting recycling waste is visibly different from residual waste collection vehicles and materials are sorted as they are placed in the van, giving a clear message that the service is trustworthy and recyclables will not end up in landfill sites (Woodward et al., 2005). If households leave out contaminated boxes (including non-recyclable waste or placing waste in the wrong containers), they are left with a card explaining how the service works.

\subsection{Street-based design}

We chose a street based research design, using the street as the unit of analysis. The primary reason was that we expected household recycling behaviour would be influenced by other households in the street: households are more likely to recycle if they see that others in their street are doing the same and they may be influenced by social norms that emerge over recycling. We therefore anticipated that canvassing one household might have an effect on the behaviour of its neighbours in the control group, which would contaminate the experiment. A street based design reduced the possibility of such contamination.

The number of streets was determined by the coverage of the recycling service, allowing us to hold constant the level of service offered to each household. Flats and commercial properties were not included in the study because they are not eligible for the recycling service. All streets in Old Trafford and Gorse Hill with at least one residential property were eligible for inclusion in the research study. There were a total of 194 streets, with 6580 households, ranging in size from 2 households to 190, with an average of 33.9 households per street.

\subsection{The intervention}

Four canvassers were specifically recruited and trained for the task. The canvassers received one day's training on the EMERGE recycling service, the benefits of recycling, possible arguments against recycling, canvassing issues and practical issues relating to health and safety. The canvassing took place over a period of six weeks in May and June 2008 between 3pm and 7pm Monday to Friday and 11am - 3pm on Saturday. These times were chosen to maximize the number of contacts, based on previous best practice (WRAP, 2006b). After all the selected intervention streets had been canvassed once, a repeat canvass of the whole area was done, calling at all the households who had not been contacted on the first occasion. These second visits were arranged at a different time of day from the first visit to maximize contact. During the first canvass 40 per cent of households were spoken to. By the end of the second canvass, 61 per cent of households had been contacted, 2129 of the 3468 households in the intervention group. The rate of contact rate of 61 per cent compares favourably with other canvassing projects (WRAP, 2006b).

One of the four canvassers visited all households in the streets in the intervention group. The canvassing focused on three factors that are expected to influence recycling behaviour: awareness, attitudes and structural barriers (Shaw et al., 2007). Canvassers made sure householders were aware of the service by confirming the day and time of collection, explaining the variety of materials that can be recycled. They promoted positive attitudes to recycling and were enthusiastic about encouraging people to take part. They addressed barriers to recycling by providing any plastic bags as required and ordering new boxes if they were lost or missing. They dealt with any problems or queries about the service or passed any difficult queries onto an EMERGE manager. The canvassers were encouraged to be enthusiastic and conversational on the doorstep. They were provided with scripts to use as prompts but were encouraged to adapt them to their own conversational style.

Canvassers were asked to take a different approach dependent on whether the household were currently recyclers or non-recyclers (Shaw et al., 2007). Existing recyclers were thanked for using the recycling box, reminded of the variety of recyclable materials and - if they seemed enthusiastic - asked if they would like to become recycling champions. Non-recyclers were encouraged to recycle, informed of the day and date of collection and materials collected. They were then asked if they could be counted on to recycle regularly. Both groups were asked if they had any questions or concerns about the service and if they needed replacement receptacles. An information leaflet was given to every household canvassed and was also delivered to houses where no one was at home. The leaflet described what materials could be recycled, outlined the service provided, gave details of the time and day of collection and provided contact details for more information.

A $\log$ sheet was produced for each street. It listed every household on the street, with an indication of whether they currently recycle or not. Canvassers entered the date and times that the street was canvassed. The information was used to monitor when the best times to canvass were and to ensure a different time for follow up visits. Canvassers completed the sheets to show which houses had been canvassed and whether additional bags had been provided and new box requests were entered. About 500 new boxes were requested. There was space to note if there was no one in the household who spoke English well enough for the canvassing to take place. The intention had been to re-visit these households with a translator, but the number of cases was lower than anticipated (29 households) and the number of languages was very varied, so the re-visits were not undertaken. Volunteer recycling champions were noted on the sheet and contacted by EMERGE at a later date. We found that 29 people had volunteered.

\subsection{Outcome measurement}

We measured recycling behaviour by observing which households put out a recycling container for collection. Questionnaires asking people to self-report their recycling activity are sometimes used, but they tend to be unreliable, over-reporting the extent of recycling activity (Shaw et al., 2007; Timlett and Williams, 2008). The monitoring was done on the same day as the recycling collection. The monitor sat in the recycling vehicle while the crew were working and noted all the houses on the street that had placed recycling material outside the house boundary. The monitoring was repeated over three consecutive weeks: some households may not recycle weekly because of holidays or having low levels of recyclable waste. Any household who recycled at least once in the three-week period is counted as a recycler, following the most recent guidance from the Waste and Resources Action Programme, supported by the environment department, Defra (WRAP, 2006a). The participation rate of each street was calculated as the proportion of households placing material out for collection at least one week in three.

Where the impact of an intervention is being studied, measurement is usually done shortly before the intervention and 
then repeated immediately afterwards (Read, 1999). But there is often an increase in recycling in response to an intervention and then a drop off as time passes. Repeating the measurement a third time a few months later can take account of this recycling decay (Woodward et al., 2005) and test whether habits have been formed and sustained. Participation in the recycling scheme was measured for all households in the intervention and control groups at three time points: in March/April 2008 prior to the canvassing, in July 2008 after its completion, and in October 2008 to test the habit effect. Monitoring was not done at bank holidays (because services were disrupted) or during school holidays (when some households might be away). We did not take any account of the movement of households in and out of the area during the study period; we assume there to have been similar levels of population turnover in the treatment and control groups.

\subsection{Sample size and randomization}

Prior to the randomization, in association with the Trials Unit at the University of York, we estimated that we would have 80 per cent power to show a difference of 11 per cent between the two groups assuming an estimate of the correlations between the pre and post recycling rates of 0.8 , based on a small sample of existing data, which we had from EMERGE. If the correlation turned out to be higher then our power would increase or the difference we could detect would fall.

The data was handed over to the York Trials Unit for randomization, using the SPSS random sampling function, to an intervention and control group of equal size. The data was stratified by district (Old Trafford or Gorse Hill) and street length prior to randomization. $^{2}$ The treatment group contained 3468 households in 97 streets and the control group contained 3112 households in 97 streets. We report the CONSORT participant flow diagram in Fig. 1.

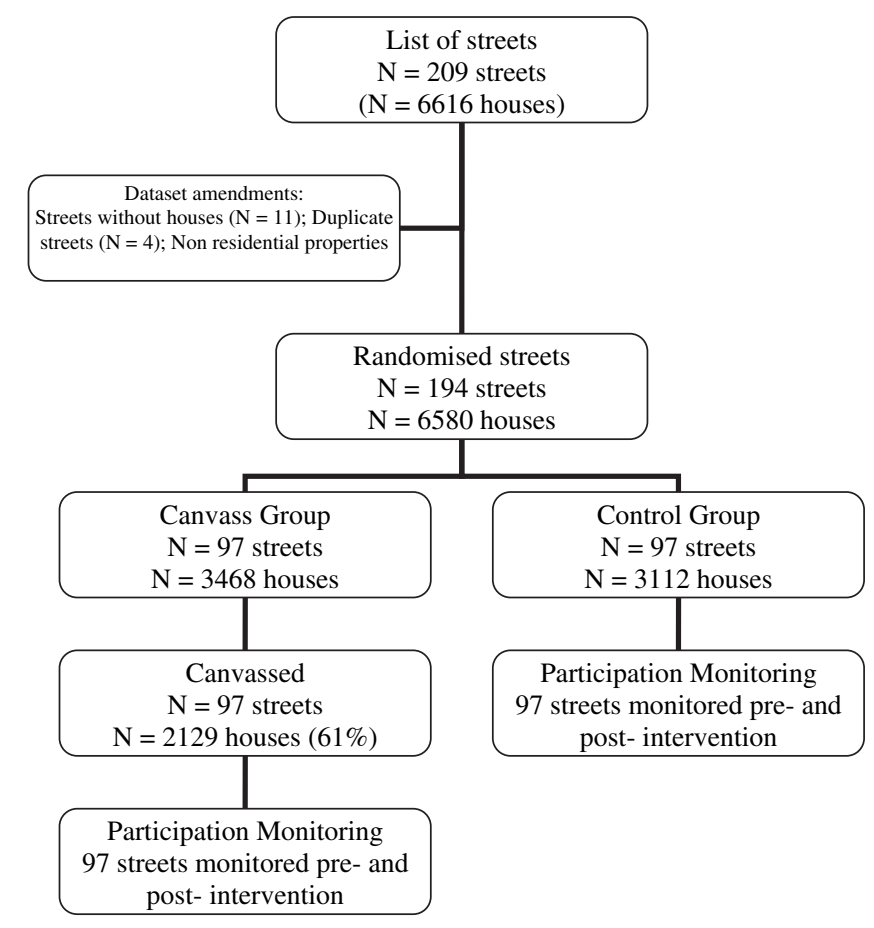

Fig. 1. CONSORT participant flow diagram.

\footnotetext{
${ }^{2}$ We thank Professor David Torgerson of the York Trials Unit, Department of Health Sciences, University of York, who executed the randomization.
}

\subsection{Blinding}

Households were not informed that they were taking part in a research study: those in the canvassed group did not know that some other streets were not being canvassed and those in the control group did not know that some other streets were being canvassed. Both groups were blind to the fact that their recycling was being monitored. This was ethically approved because no personal data was collected during the study. The canvassers who administered the intervention were not blind: they knew they were delivering the canvassing as part of a research study and understood that the canvassed streets would be compared to control streets. They were encouraged to be very careful in implementation to avoid contaminating any of the control streets by canvassing them in error. The three sets of participation monitoring were each done by a different person, none of whom were involved in any other aspect of the project, and who were unaware which streets were in the treatment and control groups. The members of the recycling collection crew were aware of the research project, but did not know which streets were in the treatment and control groups.

\subsection{Data and variables used in the analysis}

The dataset has fifteen super output areas, boundaries used by the UK Office for National Statistics to provide statistics at a local level. The dataset has two levels, with level 1 units being the streets and level 2 units being the super output areas. The data is longitudinal in the sense that the participation rate was measured on three occasions: prior to the canvassing campaign, immediately afterwards and three months later.

The outcome variable is the follow-up (or post-intervention) recycling participation rate, the percentage of households per street observed placing recyclable material out for collection at least once in three weeks. The explanatory variables include 4 street level variables and 2 super output area level covariates. The street level variables are: canvass group: coded $0=$ not canvassed, $1=$ canvassed; baseline participation rate: percentage of households per street observed placing recyclable material out for collection at least once in three weeks at time 1 (prior to the canvassing campaign); times: coded 1 = first follow-up participation rate, 2 = second follow-up participation rate; street size: total number of households in a street. The super output area level covariates are: percentage of population that is non-white (source: 2001 census, Office for National Statistics); Index of Multiple Deprivation (IMD) score: higher score means greater deprivation (source: 2007 index, Office for National Statistics). Intention to treat analysis was adopted: all of the households in the intervention group were included in the analysis, whether or not they were actually canvassed. Table 2 contains the descriptive statistics.

\section{Results}

\subsection{Descriptive statistics}

The descriptive statistics in Table 2 suggest that the mean participation rate in the canvassed streets rose from 47.7 per cent before the campaign to 52.0 per cent immediately afterwards and then rose again to 52.6 percent three months later. Among the control group streets the mean participation rate fell from 54.0 per cent to 52.9 per cent but then rose to 57.2 per cent. When comparing first follow-up to baseline, recycling participation in the canvassed group rose by 4.3 per cent whilst the control group fell by 1.1 per cent, so overall, in the short term, the treatment group improved its recycling by 5.4 per cent in comparison to the control group. When comparing second follow-up to baseline, recycling participation in the canvassed group rose by 4.9 per cent and the 
Table 2

Table of summary statistics.

\begin{tabular}{llrrlc}
\hline Variable & Obs & Mean & Std. Dev. & Min & Max \\
\hline Control Group & & & & & \\
Baseline recycling rate & 97 streets & 0.540 & 0.205 & 0 & 1 \\
1st follow-up rate & 97 streets & 0.529 & 0.195 & 0 & 1 \\
2nd follow-up rate & 97 streets & 0.572 & 0.212 & 0 & 1 \\
Street Size (no. of houses) & 97 streets & 32.082 & 28.274 & 2 & 175 \\
\% of population non-white & 97 streets & 0.351 & 0.192 & 0.103 & 0.702 \\
Multiple deprivation score & 97 streets & 0.375 & 0.090 & 0.266 & 0.527 \\
Canvass Group & & & & & \\
Baseline recycling rate & 97 streets & 0.477 & 0.207 & 0 & 1 \\
1st follow-up rate & 97 streets & 0.520 & 0.202 & 0 & 1 \\
2nd follow-up rate & 97 streets & 0.526 & 0.206 & 0 & 1 \\
Street Size & 97 streets & 35.753 & 33.727 & 2 & 190 \\
\% of population non-white & 97 streets & 0.358 & 0.192 & 0.103 & 0.702 \\
Multiple deprivation score & 97 streets & 0.382 & 0.090 & 0.269 & 0.527 \\
\hline
\end{tabular}

Note: Baseline recycling rate measured before canvassing, 1st follow-up rate measure immediately after canvassing, 2nd follow-up rate measured three months after canvassing.

control group rose by 3.2 per cent, so overall, in the longer term the treatment group improved its recycling by 1.7 per cent in comparison to the control group. So, among those streets that were canvassed, the mean number of households taking part in recycling rose immediately after the canvassing. The rise was not only sustained, but rose three months later. Meanwhile, among the streets that were not canvassed, the mean number of households taking part in recycling fell slightly after the intervention, but it then rose, so that three months later participation was higher than at the start. Table 3 presents the differences in the means across the whole time period. The change within the treatment group was significant, but the change in the control group was not. The difference of 1.7 per cent between the baseline and the follow up two periods later was not significant $(p<0.1)$. When compared to the control group, the effect of the canvassing lessened over time.

Table 3

Pre-Post changes on recycling participation rate of streets by group - PostCanvassing and Follow-up rate 3 month after intervention.

\begin{tabular}{lll}
\hline & $\begin{array}{l}\text { Post-canvassing } \\
\text { Mean (St. Err.) }\end{array}$ & $\begin{array}{l}\text { Follow-up (3 month later) } \\
\text { Mean (St. Err.) }\end{array}$ \\
\hline Control $(\boldsymbol{n}=\mathbf{9 7})$ & $-0.011(0.015)$ & $-0.032(0.013)$ \\
Treatment $(\boldsymbol{n}=\mathbf{9 7})$ & $-0.043(0.018)$ & $-0.049(0.015)$ \\
Difference & $-0.054(0.024)$ & $-0.017(0.019)$ \\
$\begin{array}{l}\text { Paired sample } \boldsymbol{t} \text {-test } \\
\quad \text { on pre to post }\end{array}$ & $t(96)=-2.262, p<0.05^{*}$ & $t(96)=-0.857, p<0.1$ \\
\hline
\end{tabular}

Note: Difference $=$ mean (control)-mean (treatment).

These results indicate that something outside the experiment caused recycling rates to dip immediately after the campaign, but to rise three months later to higher levels than before the campaign. One reason is that at the time of the canvassing and the postcampaign monitoring the recycling collection crew was shortstaffed and there was a reliance on casual staff. The canvassers found that there was a minority of householders who complained of missed collections, rude staff, dirty boxes and pedantry over contamination. By the time of the final monitoring three months later, a permanent collection crew was in place, which might be expected to have contributed to an improved service and a consequent rise in recycling rates in both groups.

\subsection{Regression models}

We ran tests which confirmed that the follow-up measures of recycling are normally distributed, meaning the data is suitable for regression analysis. We use random-effects multilevel models (Littell et al., 1996) to take into account the two levels of our data: streets and super output areas. The models are implemented in Stata using the xtreg command, with Maximum Likelihood (ML) estimators. We assume a hierarchy of different populations exists where streets within the same super output area may be more similar in some respects to one another than streets from other super output areas. We also assume that other covariates are from a normally distributed population with means and variances differing by super output area.

The basic structure of our multilevel regression models is:

$$
\begin{aligned}
& y_{i j}=\beta_{0 j}+\beta_{1 j} \chi_{1 i j} \ldots+e_{o i j} \\
& \beta_{0 j}=\gamma_{00}+\gamma_{01} W_{j}+u_{0 j} \\
& \beta_{1 j}=\gamma_{10}+u_{1 j}
\end{aligned}
$$

where $\beta$ s are fixed effects, $\chi$ s are explanatory or independent variable terms, and $e_{o i j}$ is variance parameter for level 1 and $\gamma \mathrm{s}, W \mathrm{~s}$, and $u_{0 j}$ are for level 2 respectively.

Table 4 presents the estimates of four random-effects multilevel regression models on recycling participation rate by street. Estimates of the random part include residual errors at both level 2 (super output areas) and level 1 (streets), intraclass correlation (ICC), the squared multiple correlation $\left(R^{2}\right)$ and the fit-of-model statistic (deviance). ICC is the proportion of variance estimated at the different levels. We calculate a statistic analogous to the multiple $R^{2}$ expressed difference as a proportion for the total error variance (Hox, 2002: 64), best achieved separately for each level (Hox, 2002: 64).

We start with the multilevel regression analysis by running a baseline or intercept-only model (M0), which contains no explanatory variable, which serves as a benchmark with which other models are compared (Hox, 2002: 64). Model 1 (M1) examines the influence of the street level variables on postcanvassing recycling participation rates. Within the variable Canvass Group, there is a no significant difference between the streets that were canvassed and those in the control group, with recycling rates not being higher among the canvassed streets. This appears to reject our first hypothesis $\left(\mathrm{H}_{1}\right)$, that the canvass streets have a higher level of recycling than the control group after the recycling campaign. Model 1 also shows a very strong and significant $(p<0.001)$ positive effect of the baseline recycling participation rate (Baseline rate), confirming that there is a strong effect of habit on recycling behaviour: across both groups in the sample, a large proportion of those who recycled at the start were still recycling at the end of the experiment. The variable Times is only significant at the 10 per cent level, indicating that there were changes in recycling across the periods, but its effect was weak. The final variable in Model 1 is street size and we found no significant relationship between street size and recycling rates unlike previous studies (Harder et al., 2006).

Model 2 (M2) introduces an interaction terms between the baseline rate and the treatment in line with our hypothesis 3 that there should be a negative interaction between the treatment and the baseline rate. This has some important implications for our model, which now is more fully specified. Treatment is now positive and significant at $p<.05$ with a treatment effect of 8.3 per cent. Baseline retains its power in the model. The interaction term is negative as expected, though significant at the lower bar of 10 per cent, confirming the hypothesis about the relationship between the baseline and the treatment: streets with lower baseline recycling participation rates responded more to the canvassing than streets with a higher baseline. 
Table 4

Estimates of the recycling participation rate of streets.

\begin{tabular}{|c|c|c|c|c|}
\hline \multirow[t]{2}{*}{ Model } & \multicolumn{4}{|c|}{ Regression coefficients (standard errors) $(\beta(\mathrm{SE}))$} \\
\hline & $\begin{array}{l}\text { M0: Intercept- } \\
\text { only model }\end{array}$ & $\begin{array}{l}\text { M1: Street } \\
\text { level variables- } \\
\text { only model }\end{array}$ & $\begin{array}{l}\text { M2: M1 + } \\
\text { interaction canvass } \\
\text { group*baseline }\end{array}$ & $\begin{array}{l}\text { M3: Street level } \\
\text { variables \& area } \\
\text { covariates model }\end{array}$ \\
\hline \multicolumn{5}{|l|}{ Fixed effect } \\
\hline Intercept & $0.534^{* *}(0.022)$ & $0.133^{* *}(0.032)$ & $0.101^{* *}(0.037)$ & $0.184^{* *}(0.059)$ \\
\hline Canvass group & & $0.020(0.014)$ & $0.083 *(0.038)$ & $0.080 *(0.038)$ \\
\hline Baseline rate & & $0.700^{* *}(0.036)$ & $0.761^{* *}(0.049)$ & $0.750^{* *}(0.049)$ \\
\hline Canvass group*Baseline rate & & & $-0.122+(0.069)$ & $-0.117+(0.069)$ \\
\hline Times & & $0.025+(0.014)$ & $0.025+(0.014)$ & $0.025+(0.014)$ \\
\hline Street size & & $0.000(0.000)$ & $0.000(0.000)$ & $-0.000(0.000)$ \\
\hline Multiple deprivation score & & & & $-0.282^{*}(0.112)$ \\
\hline Percentage of non-White population & & & & $0.085+(0.052)$ \\
\hline \multicolumn{5}{|l|}{ Random effect } \\
\hline Variance of area level residual errors $\left(\sigma_{u 0 j}^{2}\right)$ & 0.005 & 0.001 & 0.001 & 0.000 \\
\hline Variance of street level residual errors $\left(\sigma_{\rho 0 i j}^{2}\right)$ & 0.036 & 0.019 & 0.018 & 0.018 \\
\hline Intraclass correlation at area level & 0.123 & 0.051 & 0.060 & 0.027 \\
\hline Explained variance at area level $\left(R_{2}^{2}\right)$ & & 0.804 & 0.773 & 0.900 \\
\hline Explained variance at street level $\left(R_{1}^{2}\right)$ & & 0.487 & 0.493 & 0.494 \\
\hline Deviance & & 268.10 & 3.256 & 6.245 \\
\hline
\end{tabular}

$+: p<0.1$.

$*: p<0.05$.

$* *: p<0.01$.

Model 3 (M3) introduces 2 super output area level covariates, the multiple deprivation score and the percentage of the population that is non-white. The equation of the final model is:

$Y_{i j}=\beta_{0 j}+\beta_{1}$ Canvass $_{\text {Group }_{j}}+\beta_{2}{\text { Baseline } \text { Rate }_{j}}$

$+\beta_{3}$ Canvass group*Baseline Rate $_{j}+\beta_{4}$ Times $_{j}$

$+\beta_{5}$ Street $\operatorname{Size}_{j}+e_{i j}$

$\beta_{0 j}=\gamma_{00}+\gamma_{01}$ Multiple Depreviation Score

$+\gamma_{02}$ Non White Rate $+u_{0 j}$

$\beta_{1 j}=\gamma_{10}+u_{1 j}$

The results of model 3 indicate that there is a significant $(p<0.05)$ and negative relationship between the multiple deprivation score of an area and recycling rates. In our sample, streets in super output areas with high levels of poverty participate less in kerbside recycling. When we control for deprivation, the streets

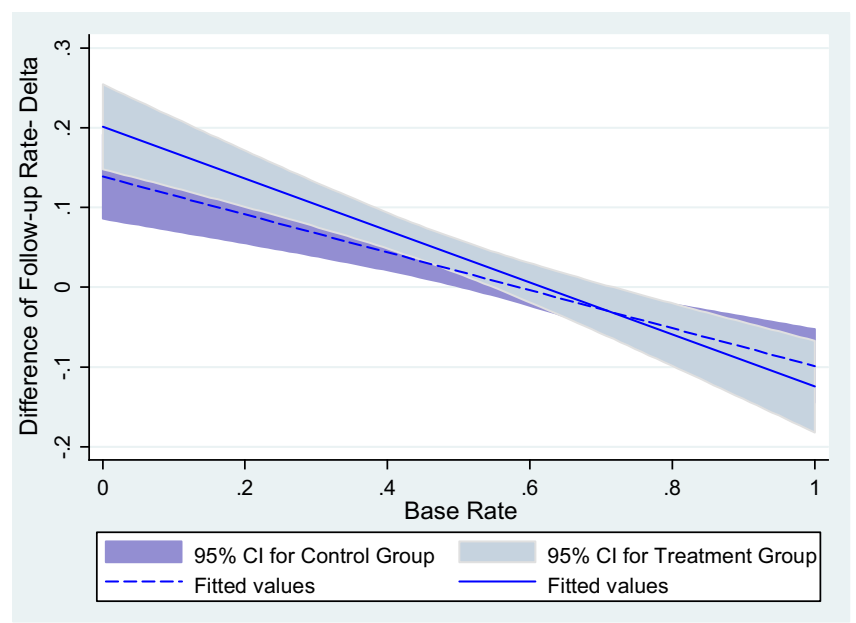

Fig. 2. Marginal effect of group to post-Intervention participation rate as base rate changes. in super output areas with a high ethnic minority population are more likely to participate in a kerbside recycling scheme than those in nearby areas that have a smaller proportion of ethnic minorities. This questions previous studies that have found no difference in recycling rates between ethnic groups, though the results are only significant at the 10 per cent level. The inclusion of these terms has no impact on the model estimates for the hypothesized terms of the treatment group, the effect over time and the interaction. In models not reported in the table, we find no influence of other interactions of treatment with habit (times), deprivation or percentage of nonwhite.

We explore the impact of the interaction term by plotting the predicted values of the interaction term with the outcome, the follow up rate (Fig. 2). This is a two-way linear prediction plot with confidence intervals. The solid line is the fitted value of treatment group while the dash line is the fitted values of control group. This figure shows that when the base rate is low there is more of an effect on participation rate in recycling. However, as base rate increases the effect of treatment decreases.

\section{Conclusion}

The research did not start out with the expectation that canvassing would lead to radical changes in behaviour because the intervention is modest. There was also the risk that an intervention might be short-term. And so it proved to be. Immediately after the canvassing, recycling in the intervention group rose by 5.4 percentage points when compared to the control group, and the effect was significant, but the effect lessened over time to just under 1.7 per cent. There is a decline in participation three months after the intervention, which shows that canvassed streets do not tend to get the habit of recycling. Nonetheless, when analyzed in regression models, recycling rose more in the treatment group than in the control group. These effects are robust to a variety of controls, such as ethnicity, deprivation and baseline measures. A limitation of our study is that we could not measure the weight of recyclables collected, so we cannot say whether the canvassing successfully encouraged households to recycle a higher proportion of their waste or whether the campaign simply encouraged them to place the bin out for collection more often. 
In terms of making an inference outside the study area, we should bear in mind that this is in an inner city area where the recycling service is comprehensive, and where there are terraced and semi-detached houses which are easy to canvass, so it may be the case that other areas either have more potential for recycling or less by this method - we cannot know. But such results are consistent with existing observational studies (WRAP, 2006b) and with the effects of door-to-door canvassing for other contexts. The randomized controlled trial is a robust test of the intervention. In the absence of confounds to the experiment - we were not aware of any - we can assume that the canvassing had a modest effect in the short term and tailed off over time.

The positive results appear to justify the street-based nature of the intervention, which may be justified because of the ease of randomizing and canvassing streets. However, we present no comparison of efficiency with a campaign based on randomizing individual properties or street blocks or neighbourhoods. Moreover, the street effects in our data were not there as expected because length of streets did not matter. Nonetheless our multilevel models showed that recycling participation rates are affected by differences in the demographic characteristics of areas. Further examination of the street and area effect could be examined in future studies.

The findings have practical significance for local authorities and others who want to promote involvement in kerbside recycling schemes. Our study indicates that a well run door-to-door canvassing campaign can successfully raise participation in a kerbside recycling scheme by $5 \%(p=0.05)$ compared to a control group. The effect however declines three months later, suggesting that canvassing and other promotional campaigns need to be repeated regularly to reinforce the recycling message. Canvassing campaigns are likely to be most successful if targeted in streets with low baseline recycling rates, relatively deprived areas, or areas with a high ethnic minority population. In our study, we estimate that the cost of the canvassing campaign was approximately $£ 24.06$ for each additional household that started recycling. ${ }^{3}$

Finally the interaction of the treatment with the baseline rate has both academic and policy implications. For academics, the prior propensity to participate is an important variable for canvassing experiments. Policy-makers may wish to know that - even though more deprived areas are less likely to recycle - low participators are more receptive to canvassing messages than high participators.

\section{Acknowledgements}

The research study is part of the Rediscovering the Civic and Achieving Better Outcomes in Public Policy project (see www. civicbehaviour.org.uk), funded by the Economic and Social Research Council, Department of Communities and Local Government and the North West Improvement and Efficiency Partnership, grant reference: RES-177-025-0002. The authors wish to thank everyone at EMERGE, our partners in this project. We thank Martin Bland, Neil Carter, Don Green, Ian Plewis, Peter Shaw, David Torgerson and two anonymous referees for their helpful comments on earlier drafts of this paper. The paper was first presented to the Randomized Controlled Trials in the Social Sciences annual conference, University of York, September 2008 and we are grateful to participants for their comments.

\section{References}

Arceneaux, K., Nickerson, D., 2009. Who is mobilized to vote? A re-analysis of eleven randomized field experiments. American Journal of Political Science 53 (1), 1-16.

Beaman, A.L., Cole, M.C., Preston, M., Klentz, B., Mehrkens Steblay, N., 1983. Fifteen years of foot in the door research: a meta-analysis. Personality and Social Psychology Bulletin 9, 181-196.

Bryce, W.J., Day, R., Olney, T.J., 1997. Commitment approach to motivating community recycling: New Zealand kerbside trial. The Journal of Consumer Affairs 31 (1), 27-52.

Burger, J.M., Caldwell, D.F., 2003. The effects of monetary incentives and labeling on the foot-in-the-door effect: evidence for a self-perception process. Basic and Applied Social Psychology 25 (3), 235-241.

Cialdini, R.B., Trost, M.R., Newsom, J.T., 1995. Preference for consistency: the development of a valid measure and the discovery of surprising behavioral implications. Journal of Personality and Social Psychology 69, 318-328.

Freedman, J.L., Fraser, S.C., 1966. Compliance without pressure: the foot-in-the-door technique. Journal of Personality and Social Psychology 4 (2), 195-202.

Green, D.P., Gerber, A.S., 2008. Get Out the Vote: How to Increase Voter Turnout. Brookings Institution Press, Washington, D.C.

Harder, M.K., Woodard, R., Bench, M.L., 2006. Two measured parameters correlated to participation rates in kerbside recycling schemes in the UK. Environmental Management 37 (4), 487-495.

Hox, J., 2002. Multilevel Analysis Techniques and Applications. Lawrence Erlbaum Associates, New Jersey.

Jackson, T., 2005. Motivating Sustainable Consumption: A Review of Evidence on Consumer Behaviour and Behavioural Change. Policy Studies Institute, London.

John, P., Brannan, T., 2008. How different are telephoning and canvassing? A get out the vote field experiment in the UK 2005 general election. British Journal of Political Science 38, 565-574.

Littell, R.C., Milliken, G.A., Stroup, W.W., Wolfinger, R.D., 1996. SAS System for Mixed Models. SAS Institute, Inc., Cary, NC.

Lyas, J.K., Shaw, P.J., Van Vugt, M., 2004. Provision of feedback to promote householders' use of a kerbside recycling scheme - a social dilemma perspective. Journal of Solid Waste Technology 30, 7-18

Martin, M., Williams, I.D., Clark, M., 2006. Social, cultural and structural influences on household waste recycling: a case study. Resources, Conservation and Recycling 48, 357-395.

Moher, D., Schulz, K., Altman, D., 2001. The CONSORT statement: revised recommendations for improving the quality of reports of parallel group randomized trials. BMC Medical Research Methodology 1 (1), 2.

Perry, G.D.R., Williams, I.D., 2007. The participation of ethnic minorities in kerbside recycling: a case study. Resources, Conservation and Recycling 49, 308-323.

Read, A.D., 1999. A weekly doorstep recycling collection, I had no idea we could! Overcoming the local barriers to participation. Resources, Conservation and Recycling 26, 217-249.

Reams, M.A., Ray, B.H., 1993. The effects of 3 prompting methods on recycling participation rates - a field-study. Journal of Environmental Systems 22 (4), 371-379.

Schultz, P.W., 1998. Changing behaviour with normative feedback interventions: a field experiment on kerbside recycling. Basic and Applied Psychology 21 (1), 25-36.

Shaw, P.J., 2008. Nearest neighbour effects in kerbside household waste recycling. Resources, Conservation and Recycling 52, 775-784.

Shaw, P.J., Lyas, J.K., Maynard, S.J., Van Vugt, M., 2007. On the relationship between set-out rates and participation ratios as a tool for enhancement of kerbside household waste recycling. Journal of Environmental Management 83, 34-43.

Shaw, P.J., Maynard, S.J., 2008. The potential of financial incentives to enhance householders' kerbside recycling behaviour. Waste Management 28 (10), 17321741.

Timlett, R.E., Williams, I.D., 2008. Public participation and recycling performance in England: a comparison of tools for behaviour change. Resources Conservation and Recycling 52 (4), 622-634.

Tucker, P., 1999. Normative influences in household waste recycling. Journal of Environmental Planning and Management 42 (1), 63-82.

Woodward, R., Bench, M., Harder, M.K., 2005. The development of a UK kerbside scheme using known practice. Journal of Environmental Management 75 (2), 115-127.

Waste \& Resources Action Programme, 2006a. Improving the performance of waste diversion schemes: a good practice guide to monitoring and evaluation. WRAP, Banbury. Available at. http://www.wrap.org.uk/ (accessed 07.03.08.).

Waste \& Resources Action Programme, 2006b. Step by step guide to door-to-door canvassing. WRAP, Banbury. Available at. http://www.wrap.org.uk/ (accessed 07.03.08.).

\footnotetext{
3 The cost of carrying out the canvassing was $£ 5605.59$ (including wages, supervision, training and mobile phone). Immediately after the canvassing, 233 additional households from the intervention group started recycling. The estimated cost per additional household is $£ 5605.59 / 233=£ 24.06$.
} 